\title{
Crystal structure of aquabis(4-methyl-5-formyl-imidazolfuranoylhydrazone)- (trinitrato)praseodymium(III) monohydrate, $\operatorname{Pr}\left(\mathrm{H}_{2} \mathrm{O}\right)\left(\mathrm{C}_{9} \mathrm{H}_{10} \mathrm{O}_{2} \mathrm{~N}_{4}\right)_{2}\left(\mathrm{NO}_{3}\right)_{3} \cdot \mathrm{H}_{2} \mathrm{O}$
}

\author{
P. M. Haba ${ }^{\mathrm{I}}$, M. Gaye*,I, A. S. Sall ${ }^{\mathrm{I}}$, A. H. Barry ${ }^{\mathrm{II}}$ and T. Jouini ${ }^{\mathrm{III}}$ \\ I Université Cheikh Anta Diop, Faculté des Sciences et Techniques, Département de Chimie, Dakar, Senegal \\ II Université de Nouakchott, Faculté des Sciences, Département de Chimie, Nouakchott, Mauritanie \\ ${ }^{\text {III }}$ Faculté des Sciences, Département de Chimie, Campus Universitaire, 1060 Tunis, Tunisie
}

Received January 27, 2004, accepted and available on-line March 10, 2004; CCDC no. 1267/1219

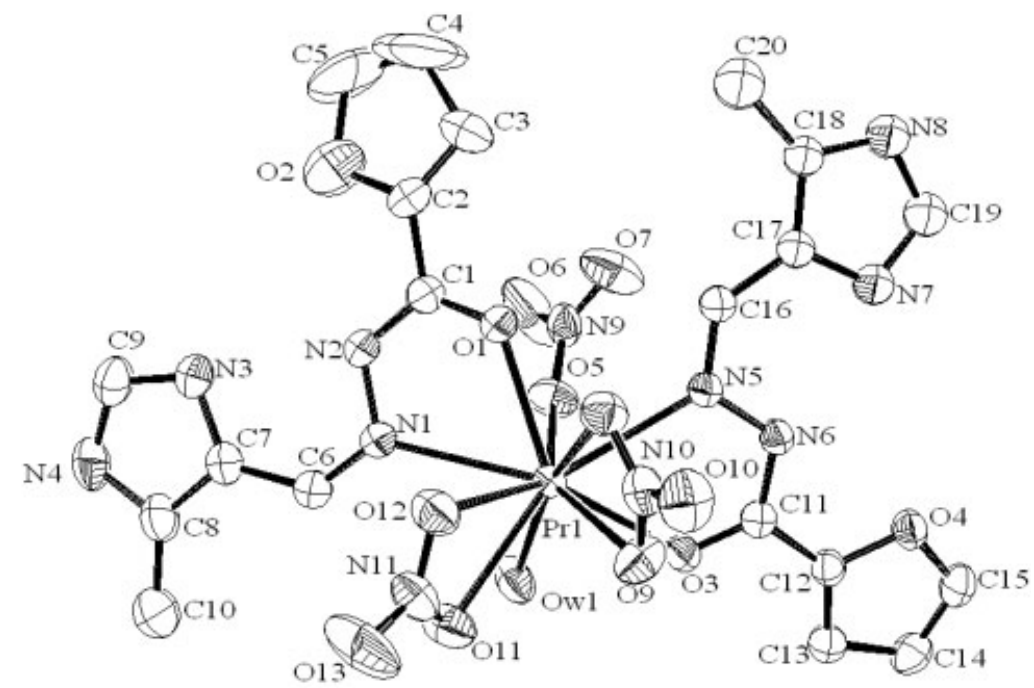

\begin{abstract}
$\mathrm{C}_{20} \mathrm{H}_{24} \mathrm{~N}_{11} \mathrm{O}_{15} \mathrm{Pr}$, monoclinic, $P 12_{1} / c 1$ (no. 14), $a=18.956(4) \AA, b=8.161(2) \AA, c=22.151(3) \AA$, $\beta=114.53(2)^{\circ}, V=3117.5 \AA^{3}, Z=4$, $R_{\mathrm{gt}}(F)=0.025, w R_{\mathrm{ref}}\left(F^{2}\right)=0.063, T=293 \mathrm{~K}$.
\end{abstract}

\section{Source of material}

4-methyl-5-formylimidazole $(10 \mathrm{mmol})$ and furanoic hydrazide (10 mmol) were dissolved in ethanol with gentle warming. The white product separated after the concentration of the solution was filtered, washed with ice cold ethanol and diethyl ether and dried in vacuo to obtain 4-methyl-5-formyl-imidazolfuranoylhydrazone $\left(\mathrm{H}_{2} \mathrm{~L}\right)$. An ethanol solution of $\operatorname{Pr}\left(\mathrm{NO}_{3}\right)_{3} \cdot 6 \mathrm{H}_{2} \mathrm{O}(2 \mathrm{mmol})$ was then added to an ethanolic solution of the ligand ( $4 \mathrm{mmol})$. After heating and stirring for two hours the praseodymium(III) complex was obtained as a yellow precipitate after evaporation of the solvent. Crystals of $\left[\mathrm{Pr}\left(\mathrm{H}_{2} \mathrm{~L}\right)_{2}\left(\mathrm{NO}_{3}\right)_{3}\left(\mathrm{H}_{2} \mathrm{O}\right)\right] \cdot \mathrm{H}_{2} \mathrm{O}$ were grown by slow evaporation from an dimethylsulfoxide solution.

\section{Discussion}

The coordination of the hydrazones to Pr results in the formation of five-membered chelating rings. In the two rings the $\mathrm{Pr}-\mathrm{N}$ bonds have the largest metal-ligand distances $(d(\mathrm{Pr}-\mathrm{N} 1)=$ 2.690(2) $\AA, d(\mathrm{Pr}-\mathrm{N} 5)=2.661(2) \AA)$. The $\mathrm{Pr}-\mathrm{O}$ bonds involving the hydrazonic oxygen have the shortest metal-ligand distances and are comparable in the two ligand molecules $(d(\mathrm{Pr}-\mathrm{O} 1)=2.439(2) \AA, d(\mathrm{Pr}-\mathrm{O} 3)=2.470(2) \AA)$. The following bonds are not altered in the complex: $\mathrm{C} 6=\mathrm{N} 1$ and $\mathrm{C} 16=\mathrm{N} 5$

\footnotetext{
* Correspondence author (e-mail: mlgayeastou@yahoo.fr)
}

are short consistent with a double bond and $\mathrm{C} 1-\mathrm{N} 2$ and C11-N6 are long consistent with a single bond. The remaining bond distances of the hydrazone moiety, as well as $\mathrm{C} 1-\mathrm{O} 1$ and $\mathrm{C} 11-\mathrm{O} 3$ are slightly different in the two ligand molecules. Two of the three nitrate moieties act as bidentate, while the last one acts as monodentate. The bond angles of the two ligands, which involve the $\operatorname{Pr}(\mathrm{III})$ ion are very similar $\left(\angle \mathrm{O} 1-\mathrm{Pr}-\mathrm{N} 1=61.91(7)^{\circ}\right.$, $\left.\angle \mathrm{O} 3-\mathrm{Pr}-\mathrm{N} 5=61.17(7)^{\circ}\right)$.

The praseodymium(III) atom is ten-coordinated, being bound to two oxygen atoms of carbonyl groups, two nitrogen atoms of the azomethine groups, five oxygen atoms of the nitrate groups and an oxygen atom of coordinated water molecule. Two possible coordination polyhedra with ten vertexes are known [1]. The coordination polyhedron around the praseodymium atom is better described as a distorted bicapped square antiprism. In fact, considering those to be a bicapped dodecahedron, severe distortions have to be taken into account.

Table 1. Data collection and handling.

\section{Crystal:}

Wavelength:

$\mu$ :

Diffractometer, scan mode:

$2 \theta_{\max }$ :

$N(h k l)_{\text {measured }}, N(h k l)_{\text {unique: }}$

Criterion for $I_{\mathrm{obs}}, N(\mathrm{hkl})_{\mathrm{gt}}$ :

$N($ param $)$ refined:

Programs: yellow prism, size $0.2 \times 0.3 \times 0.5 \mathrm{~mm}$

Mo $K_{\alpha}$ radiation $(0.71073 \AA)$

$16.49 \mathrm{~cm}^{-1}$

Enraf-Nonius CAD4, $\omega / 2 \theta$

$50.96^{\circ}$

5949,5768

$I_{\mathrm{obs}}>2 \sigma\left(I_{\mathrm{obs}}\right), 5222$

518

SHELXS-86 [2], SHELXL-97 [3], ORTEP-II [4], WinGX [5], PLATON [6] 
Table 2. Atomic coordinates and displacement parameters (in $\AA^{2}$ ).

\begin{tabular}{llllll}
\hline Atom & Site & $x$ & $y$ & $z$ & $U_{\text {iso }}$ \\
\hline $\mathrm{H}(3)$ & $4 e$ & 0.2765 & -0.1377 & 1.1679 & $0.15(3)$ \\
$\mathrm{H}(20 \mathrm{~A})$ & $4 e$ & $0.514(3)$ & $0.246(6)$ & $1.244(3)$ & $0.09(2)$ \\
$\mathrm{H}(20 \mathrm{C})$ & $4 e$ & $0.585(3)$ & $0.232(6)$ & $1.310(2)$ & $0.08(1)$ \\
$\mathrm{H}(10 \mathrm{~A})$ & $4 e$ & $-0.157(4)$ & $0.520(7)$ & $0.828(3)$ & $0.11(2)$ \\
$\mathrm{H}(10 \mathrm{~B})$ & $4 e$ & $-0.110(5)$ & $0.42(1)$ & $0.812(4)$ & $0.17(3)$ \\
$\mathrm{H}(6)$ & $4 e$ & $0.036(2)$ & $0.338(4)$ & $0.897(2)$ & $0.038(8)$ \\
$\mathrm{H}(13)$ & $4 e$ & $0.404(2)$ & $0.498(4)$ & $0.870(2)$ & $0.039(8)$ \\
$\mathrm{H}(16)$ & $4 e$ & $0.368(2)$ & $-0.052(4)$ & $1.094(2)$ & $0.031(8)$ \\
$\mathrm{H}(2)$ & $4 e$ & $0.074(2)$ & $0.161(4)$ & $1.043(2)$ & $0.05(1)$ \\
$\mathrm{H}(19)$ & $4 e$ & $0.344(2)$ & $0.510(5)$ & $1.307(2)$ & $0.06(1)$ \\
$\mathrm{H}(6 \mathrm{~A})$ & $4 e$ & $0.475(2)$ & $0.135(3)$ & $1.035(2)$ & $0.025(8)$ \\
$\mathrm{H}(15)$ & $4 e$ & $0.626(2)$ & $0.390(5)$ & $0.970(2)$ & $0.05(1)$ \\
& & & & & \\
\hline
\end{tabular}

Table 2. Continued.

\begin{tabular}{llrlll}
\hline Atom & Site & \multicolumn{1}{c}{$x$} & \multicolumn{1}{l}{$z$} & $U_{\text {iso }}$ \\
\hline $\mathrm{H}(14)$ & $4 e$ & $0.541(2)$ & $0.572(5)$ & $0.882(2)$ & $0.05(1)$ \\
$\mathrm{H}(2 \mathrm{~A})$ & $4 e$ & $0.037(3)$ & $-0.424(6)$ & $0.802(2)$ & $0.08(2)$ \\
$\mathrm{H}(2 \mathrm{~B})$ & $4 e$ & $0.070(3)$ & $-0.308(7)$ & $0.837(3)$ & $0.09(2)$ \\
$\mathrm{H}(1 \mathrm{~A})$ & $4 e$ & $0.158(2)$ & $0.456(5)$ & $0.885(2)$ & $0.05(1)$ \\
$\mathrm{H}(9)$ & $4 e$ & $-0.119(2)$ & $0.302(5)$ & $1.031(2)$ & $0.06(1)$ \\
$\mathrm{H}(1 \mathrm{~B})$ & $4 e$ & $0.228(2)$ & $0.478(5)$ & $0.907(2)$ & $0.05(1)$ \\
$\mathrm{H}(4)$ & $4 e$ & $0.242(5)$ & $-0.142(9)$ & $1.259(4)$ & $0.15(3)$ \\
$\mathrm{H}(20 \mathrm{~B})$ & $4 e$ & $0.564(4)$ & $0.379(8)$ & $1.255(3)$ & $0.13(2)$ \\
$\mathrm{H}(5)$ & $4 e$ & $0.129(4)$ & $0.03(1)$ & $1.249(4)$ & $0.18(3)$ \\
$\mathrm{H}(10 \mathrm{C})$ & $4 e$ & $-0.080(5)$ & $0.56(1)$ & $0.851(4)$ & $0.17(4)$ \\
$\mathrm{H}(8 \mathrm{~A})$ & $4 e$ & $0.387(2)$ & $0.373(5)$ & $1.240(2)$ & $0.06(1)$ \\
$\mathrm{H}(4 \mathrm{~A})$ & $4 e$ & $-0.178(3)$ & $0.433(6)$ & $0.930(2)$ & $0.07(1)$ \\
& & & & &
\end{tabular}

Table 3. Atomic coordinates and displacement parameters (in $\AA^{2}$ ).

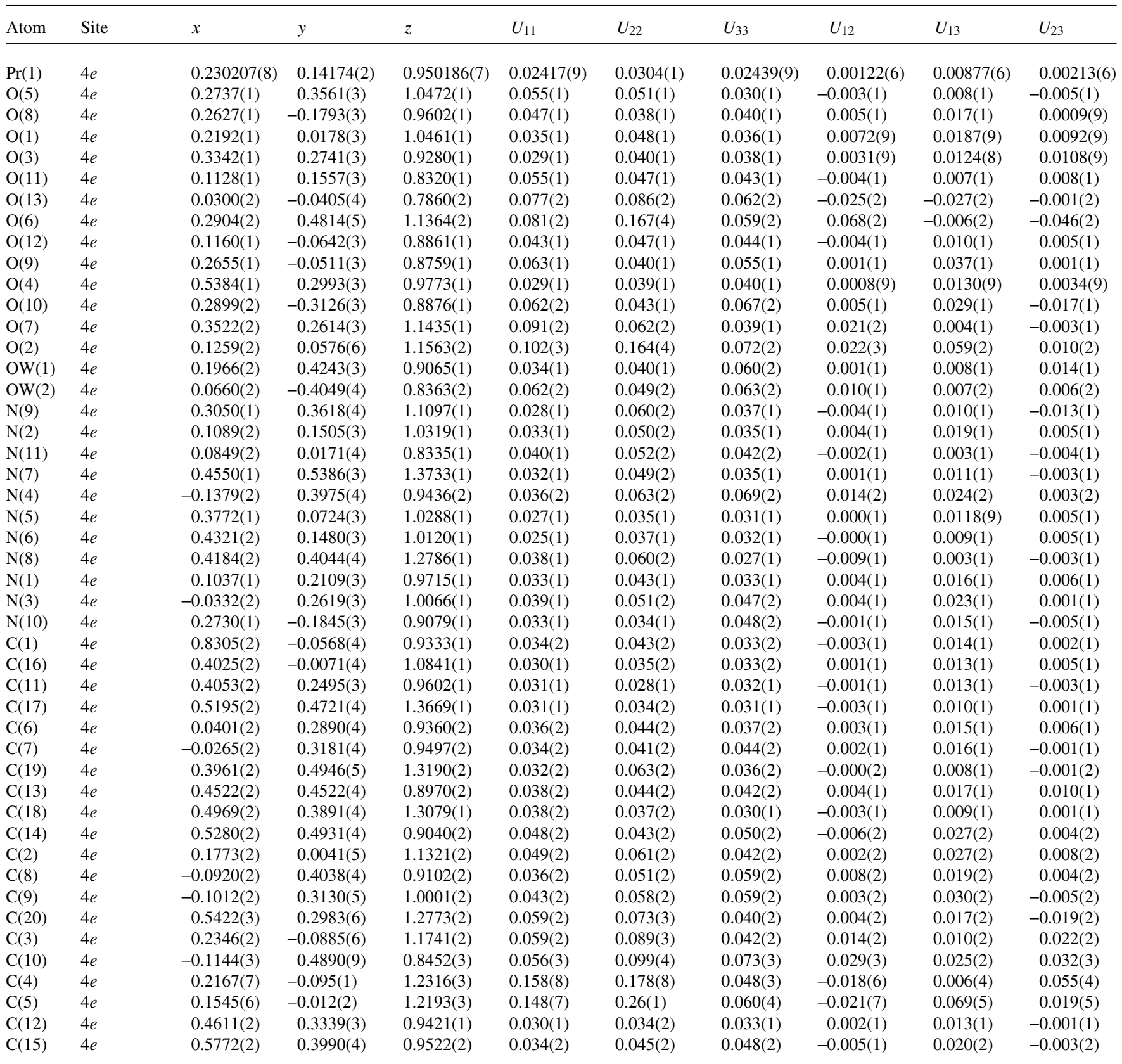




\section{References}

1. Benson, M. T.; Cundari, T. R.; Saunders, L. C.; Sommerer, S. O.: Synthesis, structure, computational studies and magnetic properties of a ten-coordinated gadolinium(III) complex. Inorg. Chim. Acta 258 (1997) 127130.

2. Sheldrick, G. M.; Kruger, C.; Goddard, R.: SHELXS-86. A direct methods program for crystal structure determination. In: Crystallographic Computing 3, pp. 175-189. Oxford University Press.

3. Sheldrick, G. M.: SHELXL-97. Program for the Refinement of Crystal Structures. University of Göttingen, Germany 1997.
4. Johnson, C. K.: ORTEP-II. Report ORNL-5138. Oak Ridge National Laboratory, Tennessee, USA 1976.

5. Farrugia, L. J.: WinGX suite for small-molecule single-crystal crystallography. J. Appl. Crystallogr. 32 (1999) 837-838.

6. Spek, A. L.: PLATON - A Multipurpose Crystallographic Tool. Utrecht University, The Netherlands 1998 